\title{
Characterization of Developmental- and Stress-Mediated Expression of Cinnamoyl-CoA Reductase in Kenaf (Hibiscus cannabinus L.)
}

\author{
Ritesh Ghosh, ${ }^{1}$ Bosung Choi, ${ }^{1}$ Byoung-Kwan Cho, ${ }^{2}$ Hyoun-Sub Lim, ${ }^{3}$ Sang-Un Park, \\ Hyeun-Jong Bae, ${ }^{5}$ Savithiry Natarajan, ${ }^{6}$ and Hanhong Bae ${ }^{1}$ \\ ${ }^{1}$ School of Biotechnology, Yeungnam University, Gyeongsan 712-749, Republic of Korea \\ ${ }^{2}$ Department of Biosystems Machinery Engineering, Chungnam National University, Daejeon 305-764, Republic of Korea \\ ${ }^{3}$ Department of Applied Biology, Chungnam National University, Daejeon 305-764, Republic of Korea \\ ${ }^{4}$ Department of Crop Science, Chungnam National University, Daejeon 305-754, Republic of Korea \\ ${ }^{5}$ Department of Bioenergy Science \& Technology, Chonnam National University, Gwangju 500-757, Republic of Korea \\ ${ }^{6}$ US Department of Agriculture, Agricultural Research Service, Invasive Insects Biocontrol \& Behavior Laboratory, \\ 10300 Baltimore Avenue, Beltsville, MD 20705, USA
}

Correspondence should be addressed to Hanhong Bae; hanhongbae@ynu.ac.kr

Received 8 October 2013; Accepted 29 December 2013; Published 26 February 2014

Academic Editors: D. Caparros-Ruiz and H. Seitz

Copyright (C) 2014 Ritesh Ghosh et al. This is an open access article distributed under the Creative Commons Attribution License, which permits unrestricted use, distribution, and reproduction in any medium, provided the original work is properly cited.

\begin{abstract}
Cinnamoyl-CoA reductase (CCR) is an important enzyme for lignin biosynthesis as it catalyzes the first specific committed step in monolignol biosynthesis. We have cloned a full length coding sequence of CCR from kenaf (Hibiscus cannabinus L.), which contains a 1,020-bp open reading frame (ORF), encoding 339 amino acids of $37.37 \mathrm{kDa}$, with an isoelectric point (pI) of 6.27 (JX524276, HcCCR2). BLAST result found that it has high homology with other plant CCR orthologs. Multiple alignment with other plant CCR sequences showed that it contains two highly conserved motifs: NAD(P) binding domain (VTGAGGFIASWMVKLLLEKGY) at N-terminal and probable catalytic domain (NWYCYGK). According to phylogenetic analysis, it was closely related to CCR sequences of Gossypium hirsutum (ACQ59094) and Populus trichocarpa (CAC07424). HcCCR2 showed ubiquitous expression in various kenaf tissues and the highest expression was detected in mature flower. HcCCR2 was expressed differentially in response to various stresses, and the highest expression was observed by drought and $\mathrm{NaCl}$ treatments.
\end{abstract}

\section{Introduction}

Lignin is an aromatic heteropolymer and normally present in the secondary thickened plant cell walls with cellulose and hemicellulose [1-3]. It is the second most abundant biopolymer in the earth, after cellulose. It gives rigidity to the plant cell wall and confers hydrophobicity to vascular elements [4]. Besides providing mechanical support, it creates a strong barrier to pathogen invasion [4]. Lignification can be induced by pathogen attack, wounding, and other abiotic stresses [5]. It is believed that emergence of lignin during evolution is a crucial adaptation for plants to live on land [6]. In addition to vascular plants, some bryophytes and red algae also contain lignin or lignin-like molecules [3].
Lignin biosynthesis is very complex and involves several enzymes. It is produced by the phenylpropanoid pathway (Figure 1). There are two major steps of lignin biosynthesis in plants: monolignol biosynthesis (coniferyl alcohol, sinapyl alcohol, and $\rho$-coumaryl alcohol) and cross-linking of the monolignols. Cross-linking is conducted by peroxidases and laccases to form polymers [6]. Intercellular synthesis of three monolignol precursors is followed by extracellular transport and polymerization as guaiacyl (G), syringyl (S), and $\rho$-hydroxyphenyl $(\mathrm{H})$ units of lignin, respectively [1$3]$. In addition to these three monolignols, other phenylpropanoids also incorporate in the polymer [4]. Composition of monolignol units and amount of lignin are highly variable between taxa and cell types, even in different environmental 


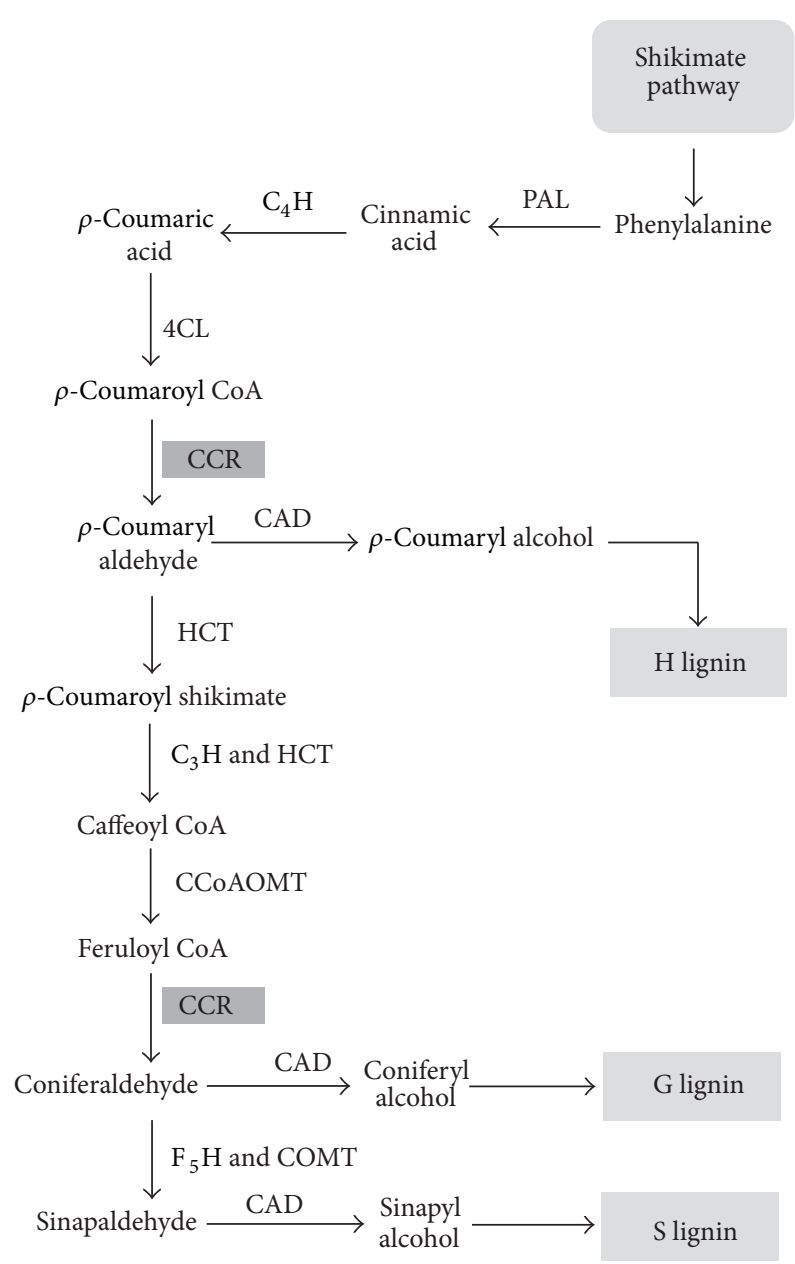

FIgURE 1: Monolignol biosynthetic pathway in dicotyledonous angiosperms. PAL, phenylalanine ammonia-lyase; $\mathrm{C} 4 \mathrm{H}$, cinnamate 4-hydroxylase; 4CL, 4-coumarate: CoA ligase; HCT, $p$ hydroxycinnamoyl-CoA: quinate shikimate $p$-hydroxycinnamoyltransferase; $\mathrm{C} 3 \mathrm{H}$, $p$-coumarate 3-hydroxylase; CCoAOMT, caffeoylCoA O-methyltransferase; CCR, cinnamoyl-CoA reductase; CAD, cinnamyl alcohol dehydrogenase; COMT, caffeic acid $O$-methyltransferase; F5H, ferulate 5-hydroxylase. Modified from Godfrey Neutelings (2011) [2].

conditions [2-4]. Lignin is problematic during pulp and biofuel production $[7,8]$. The presence of lignin decreases forage digestibility to cattle and other ruminants. Recently, researches focus on the development of genetically modified plants with less lignin content or altered composition. In this context, cinnamoyl-CoA reductase (CCR) can be a good target gene. CCR catalyzes the first specific committed step in monolignol biosynthesis [9, Figure 1]. CCR enzyme converts different cinnamoyl-CoA esters ( $\rho$-coumaroyl-CoA, caffeoylCoA, feruloyl-CoA, and sinapoyl-CoA) to corresponding cinnamaldehydes [10]. However, substrate specificity varies between different CCR enzymes from different species, even in between isoenzymes from the same species [11]. CCR orthologs were identified from various plants $[12,13]$. Plants with downregulated $C C R$ and $C C R$-like genes caused various phenotypic and developmental abnormalities: dwarfism, reduced number of seeds, small stem diameter, shorter floral stems, dark green leaves, growth delay, and collapsed xylem vessels [11-14]. Downregulation of CCR enzyme reduced lignin content in Arabidopsis and tobacco up to 50\% [7]. In tomato, downregulation of CCR also decreased lignin content and increased soluble phenolic pools [15]. CCR gene family is very diverse and can be classified as true and CCR-like [11]. Multiple homologs of CCR genes can be present in the same plant and they are involved in different function. In case of Arabidopsis, there are 11 CCR homologs [11]. Among them AtCCR1 is involved in developmental lignification, while AtCCR2 is for stress and elicitor response [4].

Kenaf (Hibiscus cannabinus L.), an annual dicotyledonous plant, is a potential source for future biomass production [16]. It has high growth rate and broad ecological adaptability and can grow in adverse environmental condition [17, 18]. Kenaf bark (35-40\% of total stem weight) is a good raw material for high quality of paper production. Its stem is composed of two types of fibers: outer long fiber $(2-6 \mathrm{~mm})$ and inner short fiber $(0.6 \mathrm{~mm})$ in $1: 3$ ratios [19]. Beside paper industry, kenaf stem is highly valuable for packaging materials, textiles, and bio-composite materials $[19,20]$. In the present study, a CCR from kenaf was isolated and characterized based on sequence homology. Expression patterns in different tissues were investigated. Effects of various stresses and elicitors on CCR expression were also investigated. For this purpose, various stresses (MeJA (methyl jasmonic acid), cold, $\mathrm{H}_{2} \mathrm{O}_{2}$, SA (salicylic acid), ABA (abscisic acid), wounding, $\mathrm{NaCl}$, and drought) were applied and the expression patterns were analyzed in 3-week-old stem tissues of kenaf plants.

\section{Materials and Methods}

2.1. Plant Materials, Stress Treatments, and RNA Isolation. Kenaf (Hibiscus cannabinus L., C-9) was grown and treated as described previously [21]. Three-week-old kenaf seedlings were treated with MeJA, cold, $\mathrm{H}_{2} \mathrm{O}_{2}, \mathrm{SA}, \mathrm{ABA}$, wounding, $\mathrm{NaCl}$, and drought. RNA was extracted as described previously [21].

2.2. Cloning. Two micrograms of RNA were used for cDNA synthesis using Superscript III First-strand synthesis kit (Invitrogen, Carlsbad, CA, USA) according to the manufacturer's instructions. Gene specific primers were used to amplify from cDNA [CCR-F, $5^{\prime}-\mathrm{AA}(\mathrm{T} /$ C)CC(A/T)GATGATCC-3'; CCR-R, $5^{\prime}$-TCCATGTA(C/G/ A)AC(T/G/C)GCACC- $\left.3^{\prime}\right]$. The degenerate primers were designed based on the consensus sequences of the CCR orthologs of Arabidopsis thaliana (NM101463), Raphanus raphanistrum (EV527773), Glycine max (AK286730), Betula luminifera (FJ410450), Capsicum annuum (EU616555), and Brassica rapa (EX046473). The PCR product was confirmed by running in a $1.2 \%$ agarose gel and then it was purified using Wizard SV Gel and PCR Clean-up System (Promega, Madison, WI, USA) and cloned into pGEM-T easy Vector (Promega). DNA sequences were analyzed by Cosmogenetech Co. (Seoul, Korea). For cloning of full length CCR ortholog, both $5^{\prime}$ and $3^{\prime}$ RACE (rapid amplification 


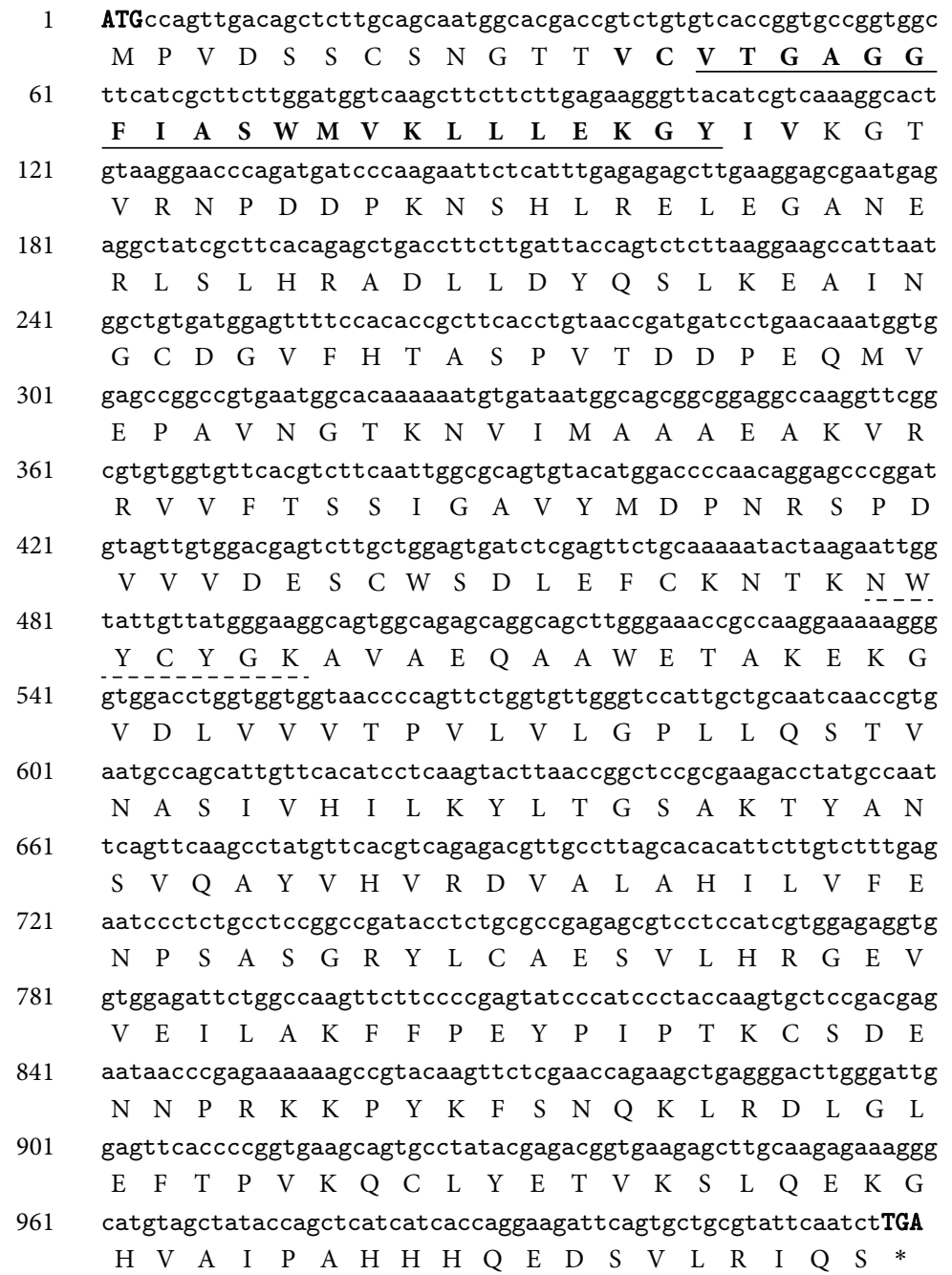

FIGURE 2: Full length CDS and deduced amino acid sequence of kenaf CCR1 ortholog. The start codon (ATG) and stop codon (TGA) are in uppercase. Putative NAD(P) binding domain and catalytic domain are underlined in solid and dashed line, respectively.

of cDNA ends) were performed using the RACE systems according to the manufacturer's instructions (Invitrogen).

2.3. Quantitative Real-Time PCR (QPCR) Analysis. QPCR was performed as described previously [22]. Mx3000P QPCR System (Agilent, Santa Clara, CA, USA) with SYBR Green QPCR Master Mix (LPS Solution, Daejeon, Korea) were used. Primers were designed using Primer 3 software of Biology Workbench (http://workbench.sdsc.edu/). Forward and reverse primers of HcCCR2 ortholog were as follows: forward primer, $5^{\prime}$ AAGTTCTCGAACCAGAAGCTG AG-3'; reverse primer, $5^{\prime}$-TGCGTCTCCACTTCCCTTAATAAACC- $3^{\prime}$. ACTIN (DQ866836), a housekeeping gene, was used as an expression control with the primer sequences: forward primer, 5'-AAGTTCTCGAACGAGAAGCTGAT-3'; reverse primer, 5' -AGTGATTTCCTTGCTCATACGGT-3'.

2.4. Data Analyses. DNA and protein sequences were analyzed using NCBI Blast (http://blast.ncbi.nlm.nih.gov/),
Biology WorkBench (ClustalW), ExPASy Proteomics Server (http://expasy.org/tools/pi_tool.html), Superfamily 1.75 (http://supfam.org/SUPERFAMILY/index.html/), SignalP 3.0 (http://www.cbs.dtu.dk/services/SignalP/), and TargetP V1.1 (http://www.cbs.dtu.dk/services/TargetP/). Phylogenetic tree was constructed using amino acid sequences by the neighbor joining method in Mega5 (http://www .megasoftware.net/).

\section{Results and Discussion}

3.1. Cloning and Sequence Analysis. We cloned a full length of CCR ortholog from kenaf (GenBank Accession number JX524276). For full length cloning, we used degenerate primers and RACE system. Sequencing data suggested that it consists of a 1,020-bp open reading frame (ORF), encoding 339 amino acids (Figure 2). The predicted molecular weight of the deduced protein is $37.37 \mathrm{kDa}$, with an isoelectric point (pI) of 6.27, as calculated by the ExPASy Proteomics Server. BLASTP search reveled that deduced protein sequence has 

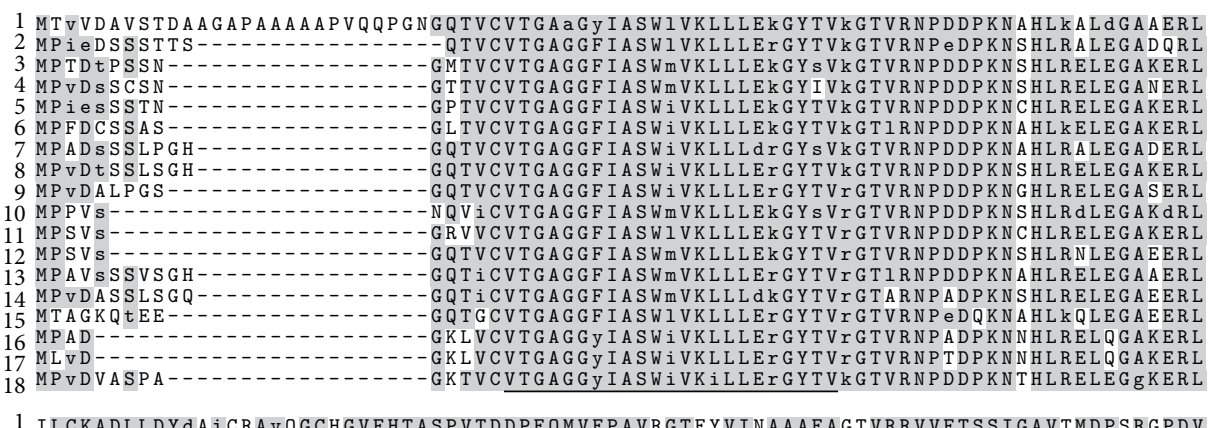

1 I LCKADLLDYdA ICRAVQGCHGVFHTASPVTDDPEQMVEPAVRGTEYVINAAAEAGTVRRVVFTSSIGAVTMDPSRGPDV 2 ILCKADLLDf SLrEAIKGCDGVFHTASPVTDNPdEMVEPAVNGTKYVIDAAAEAG-VRR IVFTSSIGAVYMDPNRSPDV 3 SLH H DLLDYPSLKEA I G CDGVFHTASPVTDDPEQMVEPAVNGTKNVImAAAEAK-VRRVVFTSS I GAVYMDPNRSPDV
4 SLHRADLLDYQSLKEAINGCDGVFHTASPVTDDPEQMVEPAVNGTKNVImAAAEAK-VRRVVFTSSIGAVYMDPRSPDV 5 SLHKADLLDY Q SLEA I G CDGVFHTASPVTDDPEQMVEPAVIGTKNVIMAAAEAK-VRRVVFTSS IGAVYMDPNRSPDV TLWKTDLLDYESLKAAIDGCDGVIHTASPVTDDPELMVEPAVDGTKNVI IAAAETK-VRRVVFTSS IGAVYMDPNRGPDV 8 TLCKADLLDYQSLIEAISGCQGVFHTASPVTDDPEQMVEPAVGTKNVINAAAEAK-VRRVVFTSSIGAVYMDPNRSPDT 9 TLCKALLDY 10 TLYK 11 TLCKADLLDYGSLEAI I CDGVFH 11 TLCrGDLLDYQSLIEA INGCDGVFHTASPVTDDPEQMVEPAVIGTKNVITAAAEAN-VRRVVFTSS I GAVYMDPSRDPEK 13 TLCKADLLD GSLIQVINGCDGVFHTASPVTDDPEEMVEPAVIGTKNVIVAAAEAK-VRRVVFTSSIGAVTMDPNRGPDT 14 TLCKADLLDYESLKEAIQGCDGVFHTASPVTDDPEEMVEPAVNGTKNVIIAAAEAK-VRRVVFTSSIGAVYMDPNKGPDV 15 TLVKADLDYNSLLNAINGCDGVFHVASPVTDDPEEMVEPAVNGTKNVIDACAVAG-VRRVVFTSSIGAVYMDPSRDYDA 16 TLHSADLLDYeALSATIDGCDGVFHTASPMTDDPETMIEPAVNGAKFVIDAAAKAK-VKRVVFTS SIGAVYMNPNRPQT

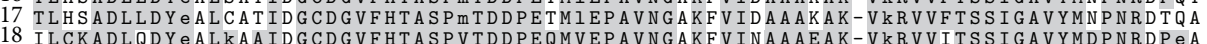

1 VVDESCWSDLEFCKKTrNWYCYGKAVAEQAAWdAArQrGVDLVVVNPVLVVGPLLQPTVNASIAHVVKYLDGSArTfANA 2 VVDESCWSDLEFCKNTKNWYCYGKAVAEQAAWEAARERGVDLVVVTPVLVLGPFLQPTVNASIVHILKYLTGSAKTYANS 3 VVDESCWSDLEFCKNTKNWYCYGKAVAEQAAWETAKEKGVDLVVVAPVLVLGPLLQSTVNAST VH ILKYLTGSAKTYANS 5 VVDESCWSDLFKN 6 VVDESCWSDLEFCKNTKNWYCYGKAVAERAAWEVAEEKGVDLVVVNPVLVLGPLLQPNVNASVVHVLKYLTGSAKTYANS 7 VVDESCWSDLEFCKNTKNWY CYGKTVAEQAAWEMAKEKEVDVVVVNPVLVLGPLLQST INASI IH ILKYLTGSAKTYANS 8 VVDESCWSDLAFCKNTKNWYCYGKAVAEQAAWEVAKEKGVDLVAVNPVLVLGPLLQSTVNASI IHILKYLTGSAKTYANS 9 VVDESCWSDLEFCKSTKNWYCYGKAVAEKAAWPEAKErGVDLVVINPVLVLGPLLQSTINASIIHILKYLTGSATYANS 10 VVDEtCWSDLEFCKNTKNWYCYGKAVAEQAAWdEAKVIGVDLVVVNPVLVLGPLLQHTVNASI VHVQKYLTGSAKTYANS 11 VVDEtCWSDPdFCKNTKNWYCYGKMVAEQAAWdEATEKGVDLVA INPVLVLGPLLQNTVNAS V IHILKYLTGSAKTYANS 12 VVDESCWSDLEFCKNTKNWYCYGKAVAEQAAWdEAKdKGVDLVVVTPVLVMGPLLQPTINASI IHVLKYLNGSAKTYANS 13 VVDESCWSDLEFCKNTKNWYCYGKAVAEQAAWAEAKEKGVDLVVVNPVLVLGPLLQPTVNASI IH ILKYLTGSTQTYANS 14 V I DESCWSDLEFCKNTKNWYCYGKAVAEQAAWdMAKEKGVDLVVVNPVLVLGPLLQPTVNAS I TH ILKYLTGSAKTYANS 15 I VDENCWSNLd YCKETKNWYCYGKTVAEKAAWERAKdKGIDLVVVNPCVVLGPVLQSSINASIIHILKYLTGSAKTYANS 16 IVDESCWSDLAFCKNTKNWYYGKMVEQSAWETAKAKGVDLVVINPVLVLGPPLQSAVNASIVHILKYLTGSAKTYANL 18 VVDESCWSDLAFCKNTKNWYCYGKMVAEQAAWETAKEKGVDLVVINPVLVLGP LQPTINASIYHVLKYLTGSAKTYANL

1 VQAYVDVRDVADAHIRVIESPRASGRYLCAERVLHREAVVR ILAKLFPEYPVPTICSDEVNPRKQPYKFSNQKLTDLGLE

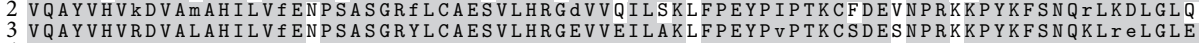
4 VQAYVHVRDVALAHILVIENPSASGRYLCAESVLHRGEVVEILAKFFPEYPIPTKCSDENNPRKKPYKFSNQKLIDLGLE 5 VQAYVHVRDVALAHILVYENPSASGRYLCAESVLHRGEVVEILAKFFPEYPIPTKCSDEKNPRAKPYKFTNQKLIDLGLE 6 VQAYVHVRDVALAHILVLETPSASGRYLCAEAVLHRGDVVQILAKLFPEYPIPTMCSDEKNPRAKPYKFSNQKLKDLGLE 7 VQAY IHVKDVALSHILVIENPSAAGRYLCAESVLHREVVEILAKLFP YPVPTKCSDEKNPRAKAYKFSCQKLKDLGLE

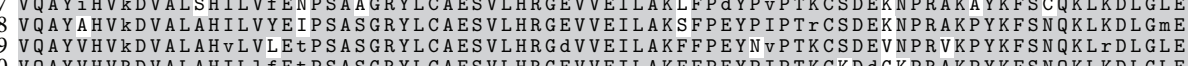
10 VQAYHVKDVALAHVLVLETPSASGRYLCAESVLHRGdVVEILAKFFPEYNVPTKCSDEVNPRVKPYKFSNQKL TDLGLE

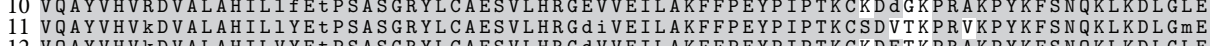
12 VQAYVHVKDVALAHILVYTPSASGRYCAESVLHRGVVILAKFFPEPIPTKCKDETKPRAKPYKFS QKLKDLGLE 13 VQAYVHVKDVALAHILVYETPSASGRYLCAESVLHRG DVVEILAKFFPEYPIPNKCKDNGKPRAEPYKFTNQKLIDLGLE 14 VQAYVHVRDVALAHILVAETPSASGRYLCSESVLHRGVVEILAKFFPEYPIPTKCSDEKNPRKQPYKF N QKL IDLGFE 15 VQAYVHVRDVAEAHILVYESPSASGRYLCAESVLHRGdVVdLLASMFPQYPIPTKVKE dGKPRVKPWKVSNQKLKDLGLE 16 TQVYVDVRDVALgHVMVYESSASGRYILAETALHRGEVEILAKFFPEYPIPIKCSDEKNPRAKPYKFTTQKIKDLGLE 17 TQVYVDVRDVAL gHVLVYEAPSASGRY IFAEtALDRGEVVEILAKFFPEYPIPTKCSDEKNPRAKPYKFtTQKiKDLGLE
18 TQAYVDVRDVALAHVLVYEAPSASGRLLAESARHGEVVEILAKLFPEPIPTKCKDEKNPRAKPYKFtNQKIKDLGLE

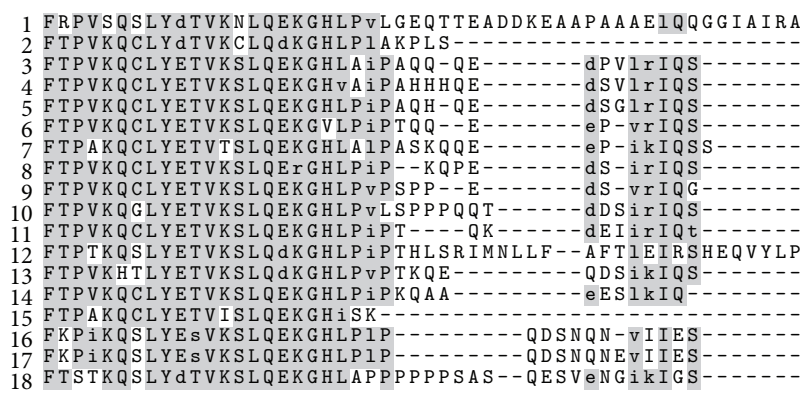

FIgURE 3: Multiple alignment of the deduced amino acid sequences of kenaf CCR ortholog with other plants by using ClustalW and BOXSHADE sequence alignment program in Biology WorkBench. Identical and similar amino acids are highlighted with gray. Conserved $\mathrm{NAD}(\mathrm{P})$ binding domain and catalytic domain are underlined in solid and dashed line, respectively. GenBank accession numbers are represented as follows: (1) Saccharum officinarum (CAA13176), (2) Cinnamomum osmophloeum (AFG26325), (3) Hibiscus cannabinus (ADK24219), (4) Hibiscus cannabinus (JX524276), (5) Gossypium hirsutum (ACQ59094), (6) Betula luminifera (ACJ38670), (7) Linum album (CAD29427), (8) Hevea brasiliensis (ADU64758), (9) Eucalyptus gunnii (CAA56103), (10) Codonopsis lanceolata (BAE48787), (11) Solanum lycopersicum (NP001234612), (12) Vaccinium corymbosum (ACI14382), (13) Pyrus pyrifolia (ADK62523), (14) Populus trichocarpa (CAC07424), (15) Pinus massoniana (ACE76870), (16) Brassica napus (AEK27156), (17) Arabidopsis thaliana (AAG53687), and (18) Arabidopsis thaliana (NP173047). 


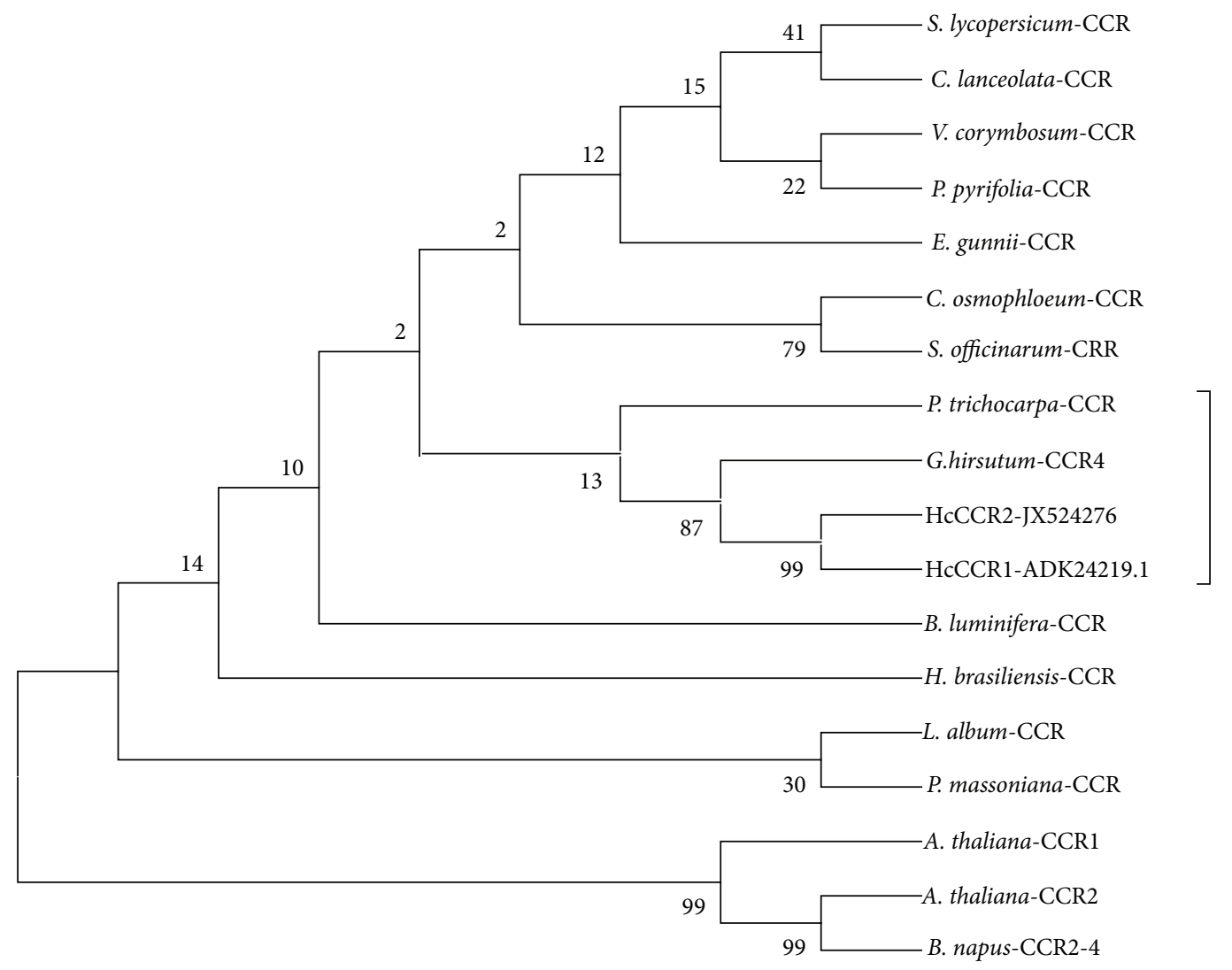

FIGURE 4: Phylogenetic analysis of the deduced amino acid sequences of kenaf CCR ortholog and other plants. The tree was constructed by the neighbor-joining method of ClustalW and Mega5. The numbers at the nodes indicate bootstrap values from 1000 replications. GenBank accession numbers are represented as follows: Solanum lycopersicum (NP001234612), Codonopsis lanceolata (BAE48787), Vaccinium corymbosum (ACI14382), Pyrus pyrifolia (ADK62523), Eucalyptus gunnii (CAA56103), Cinnamomum osmophloeum (AFG26325), Saccharum officinarum (CAA13176), Populus trichocarpa (CAC07424), Gossypium hirsutum (ACQ59094), Hibiscus cannabinus (JX524276), Hibiscus cannabinus (ADK24219), Betula luminifera (ACJ38670), Hevea brasiliensis (ADU64758), Linum album (CAD29427), Pinus massoniana (ACE76870), Arabidopsis thaliana (NP173047), Arabidopsis thaliana (AAG53687), and Brassica napus (AEK27156).

high similarities with other plant CCR sequences. Among them, one is another CCR ortholog from kenaf (ADK24219). According to Target $\mathrm{P}$ analysis, JX524276 proteins have no signals for subcellular localization, which suggests that our CCR protein is probably cytoplasmic. Previous study also showed that OsCCR1-GFP localized to the cytoplasm when it was transiently expressed in rice protoplast [23]. Signal P 3.0 analysis also showed no significant signal peptides at $\mathrm{N}$ terminal which suggests that JX524276 probably codes a nonsecretory protein. Multiple alignments of CCR protein sequences showed high sequence identities with other CCRs, up to $73 \%$ (Figure 3). Among them Gossypium hirsutum (ACQ59094) is the highest with 90\% identity. The alignment result also showed two highly conserved motifs: NAD(P)binding domain at N-terminal (VTGAGGFIASWMVKLLLEKGY) and probable catalytic domain (NWYCYGK) $[12,13]$. Consensus sequence for $\mathrm{NAD}(\mathrm{P})$ binding domain is VTGA(G/A)G(F/Y)(I/L)ASW(I/L/M)VK(L/I)LL(E/D)(K/ R)GY. Putative catalytic domain (NWYCYGK) is fully conserved among the species. Superfamily result also predicted that this kenaf CCR belongs to NAD $(\mathrm{P})$ binding Rossmannfold domain containing protein. Previous literature suggested that all plant CCRs can be broadly classified in two groups: CCR and CCR-like $[4,11]$. It is predicted that only one or two true CCR genes are present in plant for lignin biosynthesis during development, whereas others are backup for the real one [11]. As an example, experimental evidence showed that Arabidopsis has only two real CCR genes out of eleven CCR homologs [9]. AtCCR2 expression was increased in Arabidopsis ccrl mutant and function was partly compensated [14]. CCR enzyme converts different cinnamoyl-CoA esters, such as $\rho$-coumaroyl-CoA, caffeoyl-CoA, feruloyl-CoA, 5hydroxyferuloyl-CoA, and sinapoyl-CoA, to corresponding cinnamaldehydes [10]. However, substrate specificity varies between different CCR enzymes from different species, even in between isoenzymes from the same species [11]. In order to study the evolutionary relationships among different CCR sequences from various plants, a phylogenetic tree was constructed (Figure 4). Among 18 members of plant CCR proteins, both of kenaf CCR orthologs showed the closest relationship to Gossypium hirsutum (ACQ59094) and Populus trichocarpa (CAC07424). These results indicate that we successfully cloned a CCR ortholog from kenaf. From now 


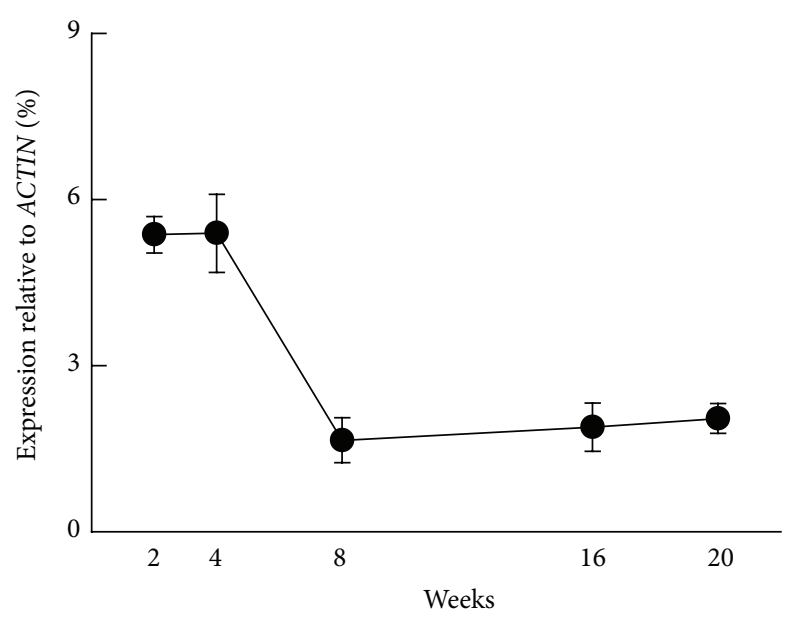

Developmental stages

(a)

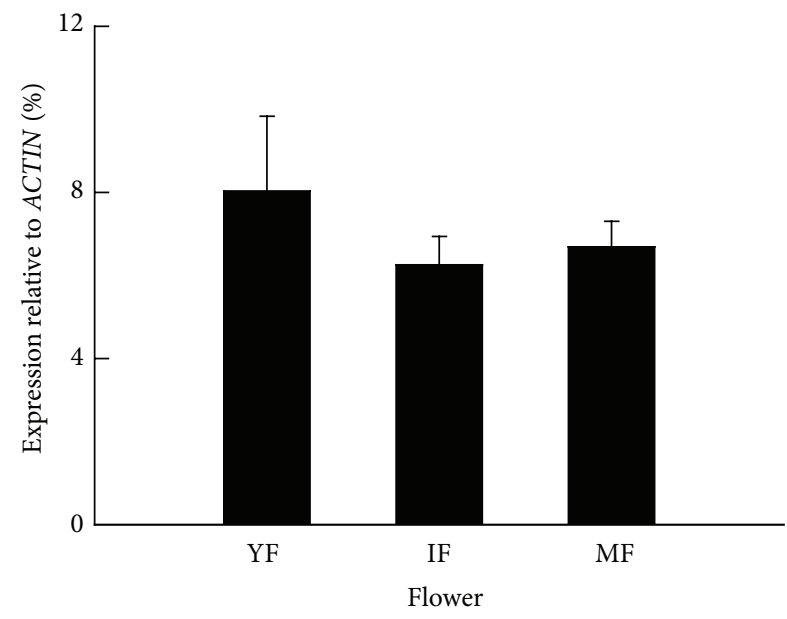

(c)

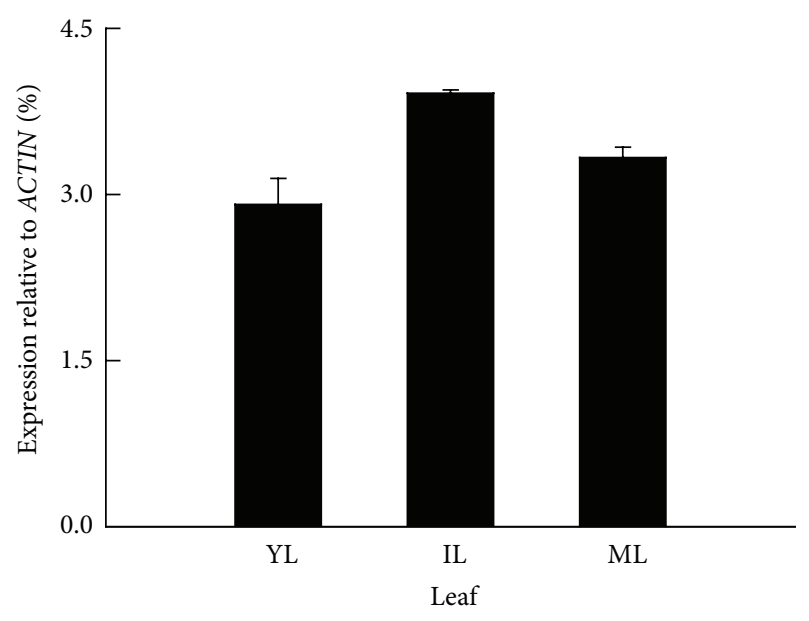

(b)

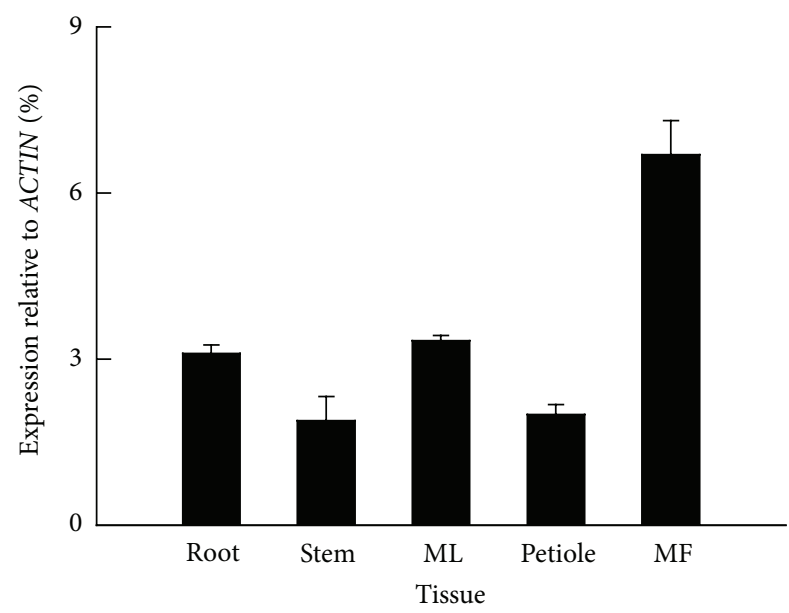

(d)

FIGURE 5: Transcript expression patterns of HcCCR2 in various tissues and organs during developmental stages. Relative transcript levels were measured using QPCR and ACTIN transcript were used as internal control. The transcript levels of kenaf CCR ortholog were adjusted after deduction of the control transcript level: (a) during stem development (2, 4, 8, 16, and 20 weeks after sowing), (b) during leaf development (YL, young leaf; IL, immature leaf; ML, mature leaf), (c) during flower development (YF, young flower; IF, immature flower; MF, mature flower), and (d) expression pattern in various tissues and organs from 16-week-old kenaf plants. Bars show means \pm standard error of 3 biological replications.

on, ADK24219 and JX524276 are designated as HcCCR1 and HcCCR2, respectively.

3.2. Analysis of Tissue Specific Expression of HcCCR2. We investigated the expression patterns of HcCCR2 transcripts in different tissues (Figure 5). During stem development, HcCCR2 was highly expressed up to 4 weeks. Then it was sharply downregulated in 8-week-old plants and maintained its steady state up to 20 weeks (Figure 5(a)). HcCCR2 did not show big differential expression among different leaf tissues, though immature leaf showed higher expression compared to young and mature leaves (Figure 5(b)). In flower, HcCCR2 showed higher level of expression in young flower, compared to immature and mature flower tissues (Figure 5(c)). HcCCR2 transcripts were identified in all tissues and organs of 16week-old plants (Figure 5(d)). The expression pattern of HcCCR 2 can be divided into three classes: (1) high expression in mature flower; (2) intermediate expression in root and mature leaf; (3) low expression in stem and petiole. Higher expression at mature flower suggests that HcCCR2 might have an important role during flowering. Expression of the genes involved in lignin biosynthesis is important for fertility (pollen release) and seed dispersal (silique dehiscence) [24]. High levels of phenylpropanoid-derived compounds were also detected in Arabidopsis flowers [25]. Other phenylpropanoid pathway related genes $(C 3 H, H C T, C C o A O M T$, $P A L$, and $C 4 H$ ) also showed high expression in flower tissues of kenaf plants [21, 26-29]. CCR has important role in development. Arabidopsis CCR1 has conserved AC elements 

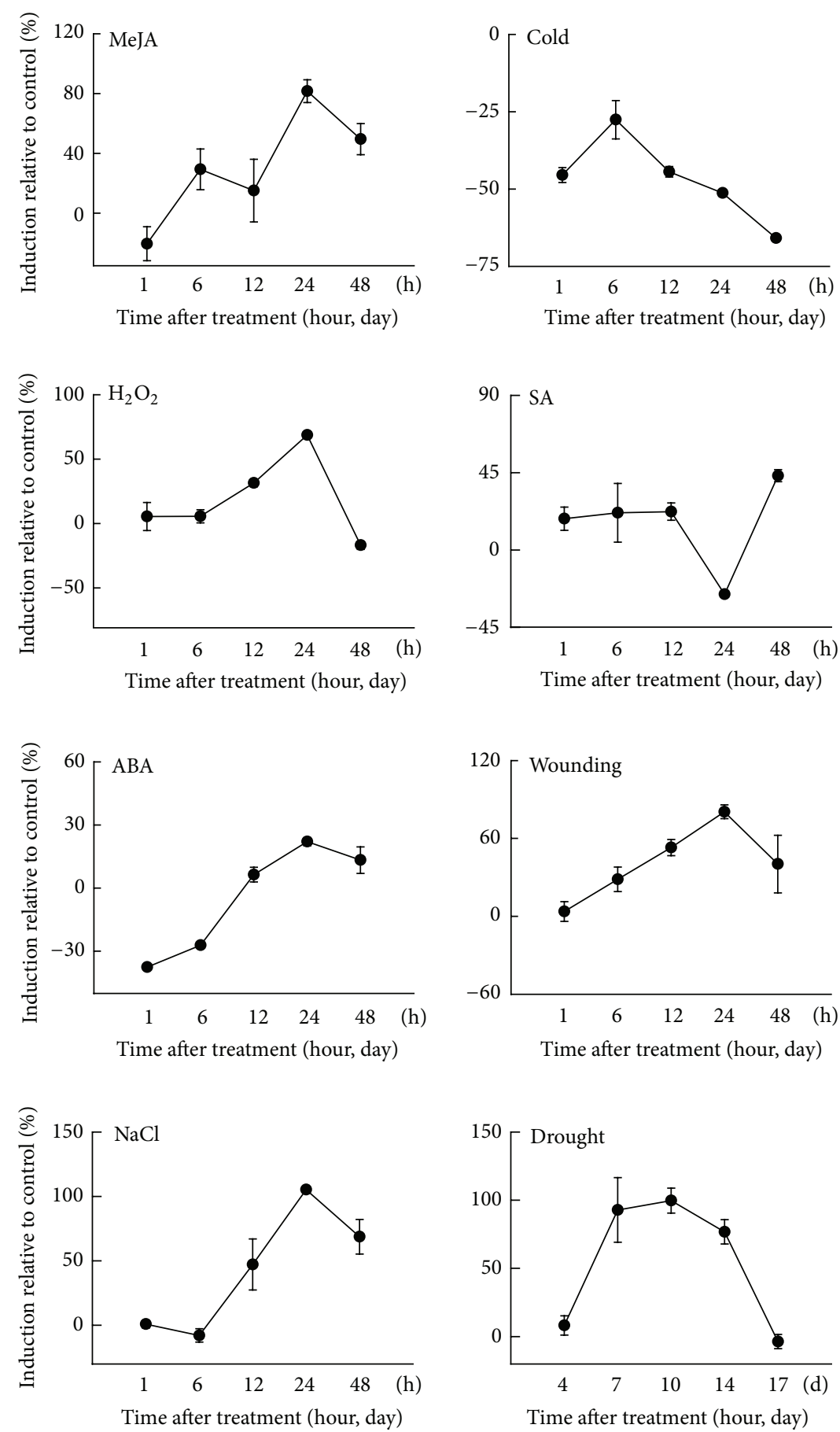

FIGURE 6: Transcript expression patterns of HcCCR2 in response to various abiotic stresses. Three-week-old stem tissues were treated with different stresses such as wounding, salicylic acid (SA), $\mathrm{NaCl}$, cold, $\mathrm{H}_{2} \mathrm{O}_{2}$, methyl jasmonate (MeJA), abscisic acid (ABA), and drought. Bars show means \pm standard error of 3 biological replications.

in promoter, which are responsible for developmental lignification [4]. Previous studies showed that CCR family has diverse expression patterns among genus, species, and even in different tissues of the same plant. In Arabidopsis, AtCCR1 was highly expressed in all tissues compared to AtCCR2 [4]. Ten poplar CCR homologs differentially expressed in bark, leaf, and xylem tissues [11]. Among them CCR2 and CCR6 showed highest expression in leaf tissues. Some CCR genes from Isatis, Ginkgo, and Norway spruce highly expressed not only in lignified tissues like stems, but also in other tissues $[13,30,31]$. Those results suggest that different CCR homologs might be involved in different cellular function.

3.3. Analysis of Stress-Regulated Expression of HcCCR2 in Stem Tissues. As plants are sessile, they are facing many adverse 
environmental conditions throughout their life span. Plants have developed advanced mechanisms to defend themselves from various biotic and abiotic stresses. Lignification is one of the most important mechanisms to combat with stresses [5]. Not much has been known about the stress-mediated CCR expression in plants. Various stresses were applied to 3-week-old kenaf plants in order to examine the expression patterns of HcCCR2 transcripts in stem tissues (Figure 6). All treatments showed differential expression of HcCCR2. Wound, $\mathrm{NaCl}, \mathrm{ABA}$, and $\mathrm{H}_{2} \mathrm{O}_{2}$ treated samples showed gradual upregulation up to $24 \mathrm{~h}$, and then the expression was decreased at $48 \mathrm{~h}$. Maximum expression was occurred at $24 \mathrm{~h}$ by all these four treatments. MeJA treated samples also showed highest expression at $24 \mathrm{~h}$. SA treated samples did not show differential expression up to $12 \mathrm{~h}$. Then it was downregulated at $24 \mathrm{~h}$, followed by upregulation at $48 \mathrm{~h}$. Cold treated samples showed quite different expression pattern. In cold treated samples $\mathrm{HcCCR} 2$ was gradually downregulated except $6 \mathrm{~h}$. Drought induced the expression up to 10 days, then it was downregulated. Among the treatments, highest accumulation of $\mathrm{HcCCR} 2$ was observed in $\mathrm{NaCl}$ (\% relative expression to $A C T I N)$ at $24 \mathrm{~h}$ and drought treatment (\% relative expression to $A C T I N)$ at 10 days. These results suggest that $H c C C R 2$ is involved in stress regulatory pathway. Previous literature also showed stress mediated differential expression of CCR in various plant species. Water deficit treatments induced the expression of $Z m C C R 1$ and $Z m C C R 2$ as well as lignin biosynthesis in maize root elongation zone [32]. This upregulation was detected both at 1 and $48 \mathrm{~h}$ after water deficit treatment. Particularly in $48 \mathrm{~h} \mathrm{ZmCCR2} \mathrm{showed}$ 10fold upregulation compared to control. MeJA treatment showed high induction of IiCCR gene from Isatis indigotica, especially at 4 and $8 \mathrm{~h}$ after treatment [13]. ABA treated plant showed downregulation of IiCCR transcript, which is similar to our cold treated sample. Other groups showed ABA induced GmCCR transcript in soybean [33]. SA treatment also induced CCR transcripts in Arabidopsis leaves and Linum album cell cultures [34]. They also showed wounding and $\mathrm{NaCl}$ mediated upregulation of GmCCR transcript. Probably different homologs are involved in different function. CCR is also responsive to various biotic stresses. For example, fungal and bacterial infection induced CCR genes: wheat TmCCR by powdery mildew; switchgrass PvCCR2 by Puccinia; Arabidopsis AtCCR2 by Xanthomonas campestris pv. Campestris [35-37]. It is hypothesized that OsRacl, one of the Rac/Rop family of small GTPases, activates CCR activities upon pathogen attack, which results in the induction of monolignol production [23]. We can divide all treatments into two categories, though they are interlinked with each other. $\mathrm{NaCl}$, drought, cold, and ABA exert similar kind of stress on the plant [38-40]. In other hand SA, JA, and wounding are related to the pathogen mediated signaling pathway [41]. Mechanical wounding and pathogen cause similar responses in plant. Both of them induce cellular phytohormone (SA, JA, and $\mathrm{ABA}$ ) and lignification to the damaged or invading sites [41, 42]. These phytohormones help to propagate and amplify the perceived signal via both synergistic and antagonistic interactions $[41,43] . \mathrm{H}_{2} \mathrm{O}_{2}$ is a very important signaling molecule for all kind of stresses.
$\mathrm{H}_{2} \mathrm{O}_{2}$ and other reactive oxygen species (ROS) can be produced by different stresses, which in turn cause random crosslinking of subunits and formation of lignin [44]. Previous experiment showed that many lignin biosynthesis genes were differentially expressed due to the various stress treatments. Cold induced phenylalanine ammonia lyase (PAL) activity in Brassica napus, cinnamate 3 -hydroxylase $(\mathrm{C} 3 \mathrm{H})$ expression in Rhododendron, and $\mathrm{HcCCoAOMT}$ and $\mathrm{HcHCT}$ expression in kenaf $[5,21,27]$ were reported.

In summary, we have cloned the full length coding sequence of cinnamoyl-CoA reductase (HcCCR2) from kenaf, which is probably homologous with the previously reported kenaf HcCCR1. HcCCR2 ubiquitously expressed in different tissues and showed differential expression in response to various stress treatments in different amplitude. According to our knowledge, in this paper, for the first time we have characterized expression pattern of kenaf CCR in different tissues and under various stress treatments, though further comparative investigation between two kenaf CCR homologs are required to know the substrate specificity and involvement in developmental lignification and stress tolerance.

\section{Conflict of Interests}

The authors declare that there is no conflict of interests regarding the publication of this paper.

\section{Acknowledgment}

This work was carried out with the support of "Cooperative Research Program for Agriculture Science \& Technology Development (PJ907054)," Rural Development Administration, Republic of Korea.

\section{References}

[1] W. Boerjan, J. Ralph, and M. Baucher, "Lignin biosynthesis," Annual Review of Plant Biology, vol. 54, pp. 519-546, 2003.

[2] G. Neutelings, "Lignin variability in plant cell walls: contribution of new models," Plant Science, vol. 181, no. 4, pp. 379-386, 2011.

[3] R. Vanholme, B. Demedts, K. Morreel, J. Ralph, and W. Boerjan, "Lignin biosynthesis and structure," Plant Physiology, vol. 153, no. 3, pp. 895-905, 2010.

[4] J. Raes, A. Rohde, J. H. Christensen, Y. Van De Peer, and W. Boerjan, "Genome-wide characterization of the lignification toolbox in Arabidopsis," Plant Physiology, vol. 133, no. 3, pp. 1051-1071, 2003.

[5] J. C. M. S. Moura, C. A. V. Bonine, J. O. F. Viana, M. C. Dornelas, and P. Mazzafera, "Abiotic and biotic stresses and changes in the lignin content and composition in plants," Journal of Integrative Plant Biology, vol. 52, no. 4, pp. 360-376, 2010.

[6] Z. Xu, D. Zhang, J. Hu et al., "Comparative genome analysis of lignin biosynthesis gene families across the plant kingdom," BMC Bioinformatics, vol. 10, no. 11, article 1471, 2009.

[7] M. Baucher, C. Halpin, M. Petit-Conil, and W. Boerjan, "Lignin: genetic engineering and impact on pulping," Critical Reviews in Biochemistry and Molecular Biology, vol. 38, no. 4, pp. 305-350, 2003. 
[8] J.-K. Weng, X. Li, N. D. Bonawitz, and C. Chapple, "Emerging strategies of lignin engineering and degradation for cellulosic biofuel production," Current Opinion in Biotechnology, vol. 19, no. 2, pp. 166-172, 2008.

[9] R. Zhou, L. Jackson, G. Shadle et al., "Distinct cinnamoyl CoA reductases involved in parallel routes to lignin in Medicago truncatula," Proceedings of the National Academy of Sciences of the United States of America, vol. 107, no. 41, pp. 17803-17808, 2010.

[10] L. Li, X. Cheng, S. Lu, T. Nakatsubo, T. Umezawa, and V. L. Chiang, "Clarification of cinnamoyl co-enzyme A reductase catalysis in monolignol biosynthesis of aspen," Plant and Cell Physiology, vol. 46, no. 7, pp. 1073-1082, 2005.

[11] A. Barakat, N. B. M. Yassin, J. S. Park, A. Choi, J. Herr, and J. E. Carlson, "Comparative and phylogenomic analyses of cinnamoyl-CoA reductase and cinnamoyl-CoA-reductase-like gene family in land plants," Plant Science, vol. 181, no. 3, pp. 249-257, 2011.

[12] K. Larsen, "Cloning and characterization of a ryegrass (Lolium perenne) gene encoding cinnamoyl-CoA reductase (CCR)," Plant Science, vol. 166, no. 3, pp. 569-581, 2004.

[13] Y. Hu, P. Di, J. Chen, Y. Xiao, L. Zhang, and W. Chen, "Isolation and characterization of a gene encoding cinnamoyl-CoA reductase from Isatis indigotica Fort," Molecular Biology Reports, vol. 38, no. 3, pp. 2075-2083, 2011.

[14] M. M. Derikvand, J. B. Sierra, K. Ruel et al., "Redirection of the phenylpropanoid pathway to feruloyl malate in Arabidopsis mutants deficient for cinnamoyl-CoA reductase 1," Planta, vol. 227, no. 5, pp. 943-956, 2008.

[15] B. Van Der Rest, S. Danoun, A.-M. Boudet, and S. F. Rochange, "Down-regulation of cinnamoyl-CoA reductase in tomato (Solanum lycopersicum L.) induces dramatic changes in soluble phenolic pools," Journal of Experimental Botany, vol. 57, no. 6, pp. 1399-1411, 2006.

[16] J. Dempsey, Fiber Crops, The University Presses of Gainesville, Gainesville, Fla, USA, 1975.

[17] H. Pande and D. N. Roy, "Delignification kinetics of soda pulping of kenaf," Journal of Wood Chemistry and Technology, vol. 16, no. 3, pp. 311-325, 1996.

[18] A. Ahmed, G. Scott, M. Akhtar, and G. C. Myers, "Biokraft pulping of kenaf and its bleachability", in Proceedings of the North American Nonwood Fiber Symposium, pp. 231-238, 1998.

[19] P. Chiaiese, G. Ruotolo, A. Di Matteo, A. De Santo Virzo, A. De Marco, and E. Filippone, "Cloning and expression analysis of kenaf (Hibiscus cannabinus L.) major lignin and cellulose biosynthesis gene sequences and polymer quantification during plant development," Industrial Crops and Products, vol. 34, no. 1, pp. 1072-1078, 2011.

[20] M. Kobaisy, M. R. Tellez, C. L. Webber, F. E. Dayan, K. K. Schrader, and D. E. Wedge, "Phytotoxic and fungitoxic activities of the essential oil of kenaf (Hibiscus cannabinus L.) leaves and its composition," Journal of Agricultural and Food Chemistry, vol. 49 , no. 8, pp. 3768-3771, 2001.

[21] R. Ghosh, B. S. Choi, M.-J. Jeong et al., "Comparative transcriptional analysis of caffeoyl-coenzyme A 3-O-methyltransferase from Hibiscus cannabinus L., during developmental stages in various tissues and stress regulation," Plant Omics Journal, vol. 5, no. 2, pp. 184-193, 2012.

[22] H. Bae, S.-H. Kim, M. S. Kim et al., "The drought response of Theobroma cacao (cacao) and the regulation of genes involved in polyamine biosynthesis by drought and other stresses," Plant Physiology and Biochemistry, vol. 46, no. 2, pp. 174-188, 2008.
[23] T. Kawasaki, H. Koita, T. Nakatsubo et al., "Cinnamoyl-CoA reductase, a key in lignin biosynthesis, is an effector of small GTPase Rac in defense signaling in rice," Proceedings of the National Academy of Sciences of the United States of America, vol. 103, no. 1, pp. 230-235, 2006.

[24] J. Thévenin, B. Pollet, B. Letarnec et al., "The simultaneous repression of CCR and CAD, two enzymes of the lignin biosynthetic pathway, results in sterility and dwarfism in Arabidopsis thaliana," Molecular Plant, vol. 4, no. 1, pp. 70-82, 2011.

[25] C. C. S. Chapple, B. W. Shirley, M. Zook, R. Hammerschmidt, and S. C. Somerville, "Secondary metabolism in Arabidopsis," in Arabidopsis, E. M. Meyerowitz, Ed., pp. 989-1030, Cold Spring Harbor Laboratory Press, Cold Spring Harbor, NY, USA, 1994.

[26] B. Choi, S. Y. Kang, H. J. Bae, H. S. Lim, W. S. Bang, and H. Bae, "Transcriptional analysis of the $\rho$-coumarate 3-hydroxylase $(\mathrm{C} 3 \mathrm{H})$ gene from Hibiscus cannabinus L. during developmental stages in various tissues and in response to abiotic stresses," Research Journal of BioTechnology, vol. 7, pp. 23-33, 2012.

[27] E. M. Chowdhury, B. S. Choi, S. U. Park, H.-S. Lim, and H. Bae, "Transcriptional analysis of hydroxycinnamoyl transferase (HCT) in various tissues of Hibiscus cannabinus in response to abiotic stress conditions," Plant Omics Journal, vol. 5, no. 3, pp. 305-313, 2012.

[28] M.-J. Jeong, B. S. Choi, D. W. Bae et al., "Differential expression of kenaf phenylalanine ammonia-lyase (PAL) ortholog during developmental stages and in response to abiotic stresses," Plant Omics Journal, vol. 5, no. 4, pp. 392-399, 2012.

[29] J. Kim, B. Choi, S. Natarajan, and H. Bae, "Expression analysis of kenaf cinnamate 4-hydroxylase $(\mathrm{C} 4 \mathrm{H})$ ortholog during developmental and stress responses," Plant Omics Journal, vol. 6, no. 1, pp. 65-72, 2013.

[30] C. Hua, L. Linling, C. Shuiyuan et al., "Characterization of a cinnamoyl-CoA reductase gene in Ginkgo biloba: effects on lignification and environmental stresses," African Journal of Biotechnology, vol. 11, no. 26, pp. 6780-6794, 2012.

[31] S. Koutaniemi, T. Warinowski, A. Kärkönen et al., "Expression profiling of the lignin biosynthetic pathway in Norway spruce using EST sequencing and real-time RT-PCR," Plant Molecular Biology, vol. 65, no. 3, pp. 311-328, 2007.

[32] L. Fan, R. Linker, S. Gepstein, E. Tanimoto, R. Yamamoto, and P. M. Neumann, "Progressive inhibition by water deficit of cell wall extensibility and growth along the elongation zone of maize roots is related to increased lignin metabolism and progressive stelar accumulation of wall phenolics," Plant Physiology, vol. 140, no. 2, pp. 603-612, 2006.

[33] H.-A. So, E. Chung, C.-W. Cho, K.-Y. Kim, and J.-H. Lee, "Molecular cloning and characterization of soybean cinnamoyl CoA reductase induced by abiotic stresses," Plant Pathology Journal, vol. 26, no. 4, pp. 380-385, 2010.

[34] M. Yousefzadi, M. Sharifi, M. Behmanesh, A. Ghasempour, E. Moyano, and J. Palazon, "Salicylic acid improves podophyllotoxin production in cell cultures of Linum album by increasing the expression of genes related with its biosynthesis," Biotechnology Letters, vol. 32, no. 11, pp. 1739-1743, 2010.

[35] N. H. Bhuiyan, G. Selvaraj, Y. Wei, and J. King, "Gene expression profiling and silencing reveal that monolignol biosynthesis plays a critical role in penetration defence in wheat against powdery mildew invasion," Journal of Experimental Botany, vol. 60, no. 2, pp. 509-521, 2009.

[36] L. L. Escamilla-Treviño, H. Shen, S. R. Uppalapati et al., "Switchgrass (Panicum virgatum) possesses a divergent family 
of cinnamoyl CoA reductases with distinct biochemical properties," New Phytologist, vol. 185, no. 1, pp. 143-155, 2010.

[37] V. Lauvergeat, C. Lacomme, E. Lacombe, E. Lasserre, D. Roby, and J. Grima-Pettenati, "Two cinnamoyl-CoA reductase (CCR) genes from Arabidopsis thaliana are differentially expressed during development and in response to infection with pathogenic bacteria," Phytochemistry, vol. 57, no. 7, pp. 1187-1195, 2001.

[38] G.-T. Huang, S.-L. Ma, L.-P. Bai et al., "Signal transduction during cold, salt, and drought stresses in plants," Molecular Biology Reports, vol. 39, no. 2, pp. 969-987, 2012.

[39] S. Mahajan and N. Tuteja, "Cold, salinity and drought stresses: an overview," Archives of Biochemistry and Biophysics, vol. 444, no. 2, pp. 139-158, 2005.

[40] M. Seki, T. Umezawa, K. Urano, and K. Shinozaki, "Regulatory metabolic networks in drought stress responses," Current Opinion in Plant Biology, vol. 10, no. 3, pp. 296-302, 2007.

[41] R. Bari and J. D. G. Jones, "Role of plant hormones in plant defence responses," Plant Molecular Biology, vol. 69, no. 4, pp. 473-488, 2009.

[42] C. Chen, H. Meyermans, B. Burggraeve et al., "Cell-specific and conditional expression of caffeoyl-coenzyme A-3-O-methyltransferase in poplar," Plant Physiology, vol. 123, no. 3, pp. 853$867,2000$.

[43] J. Ton, V. Flors, and B. Mauch-Mani, "The multifaceted role of ABA in disease resistance," Trends in Plant Science, vol. 14, no. 6, pp. 310-317, 2009.

[44] T. Karuppanapandian, J.-C. Moon, C. Kim, K. Manoharan, and W. Kim, "Reactive oxygen species in plants: their generation, signal transduction, and scavenging mechanisms," Australian Journal of Crop Science, vol. 5, no. 6, pp. 709-725, 2011. 

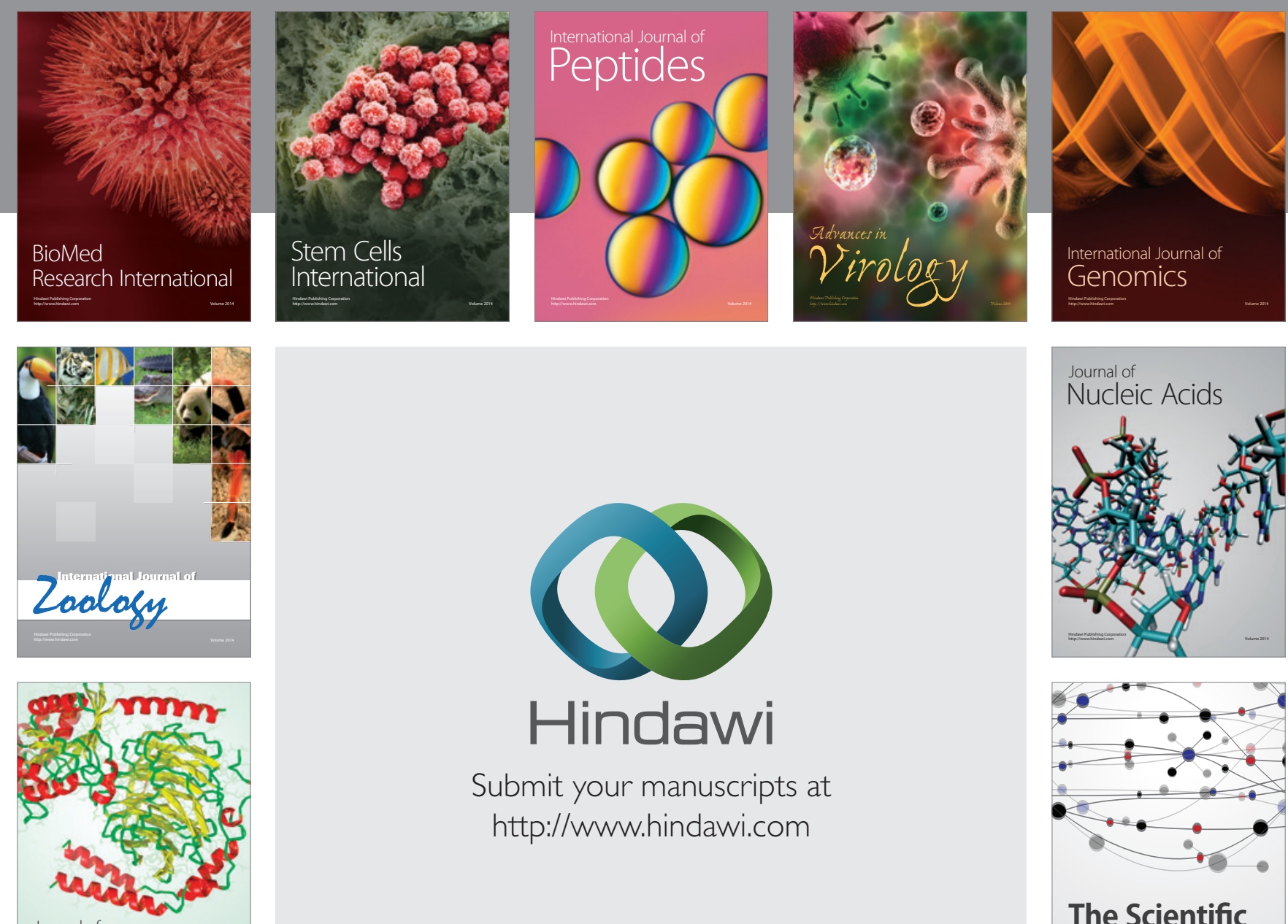

Submit your manuscripts at

http://www.hindawi.com

Journal of
Signal Transduction
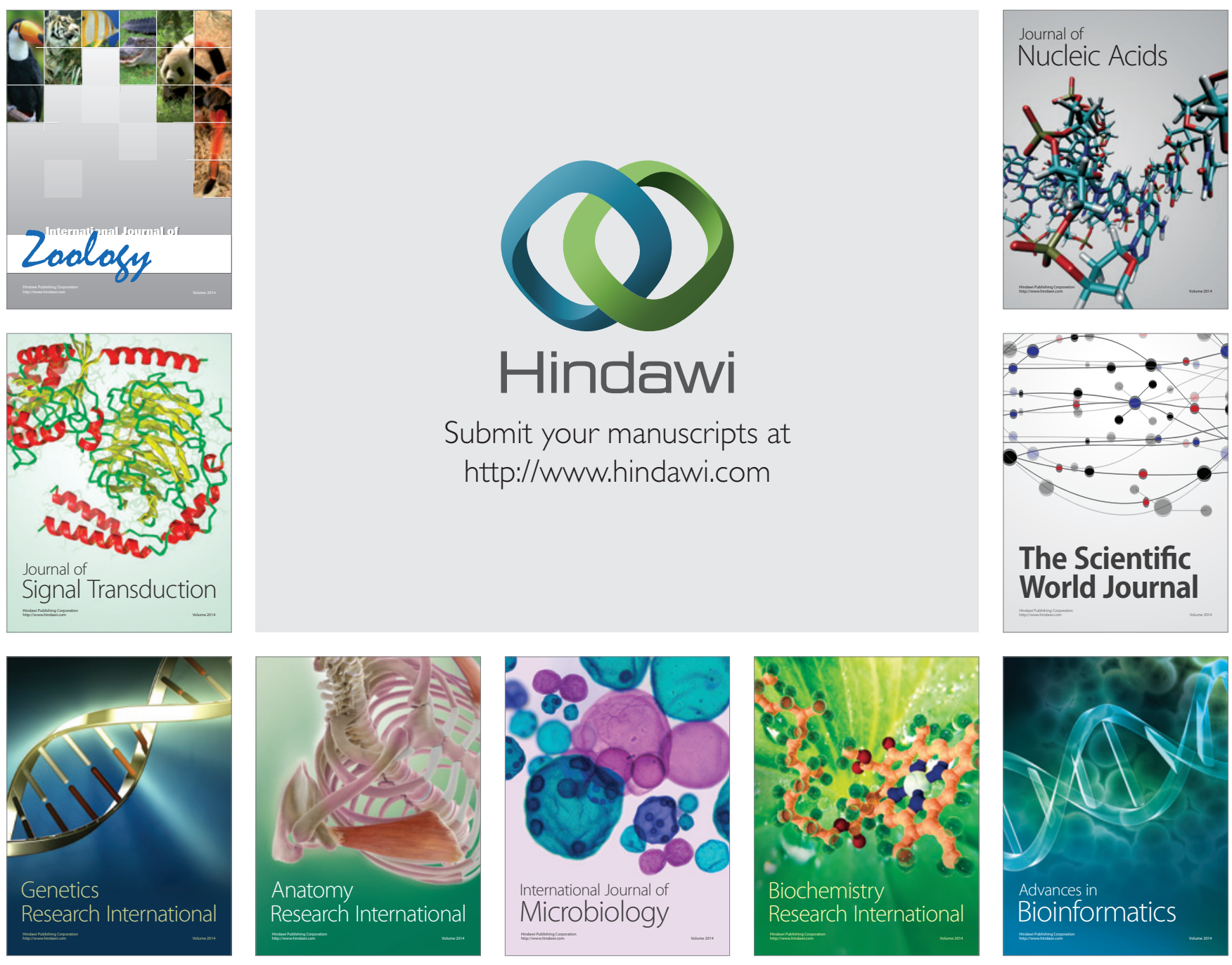

The Scientific World Journal
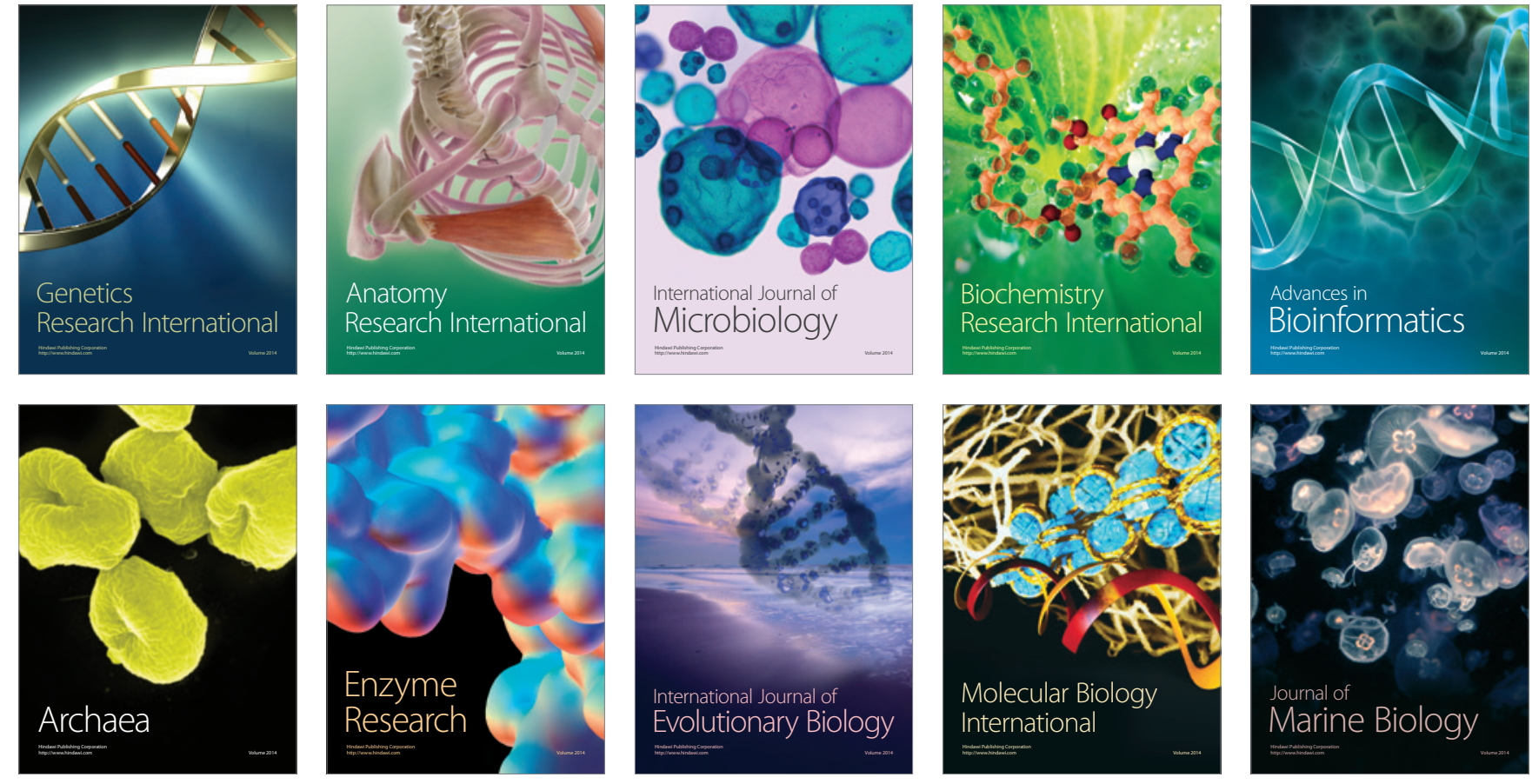